\title{
The Infectivity of Exo and Endogenous Stages of Eimeria tenella in Broilers
}

Paul Davou Kaze ${ }^{1^{*}}$, Idris Lawal ${ }^{2}$, Ajanusi Joseph ${ }^{2}$, Saidu Lawal ${ }^{2}$, Gloria Karaye ${ }^{1}$, Meriam Petrobas $^{1}$, Biallah Markus ${ }^{1}$ and Francis Sa Ayinzat ${ }^{3}$

${ }^{1}$ Department of Veterinary Parasitology and Entomology, Faculty of Veterinary Medicine, University of Jos, Nigeria

${ }^{2}$ Department of Veterinary Parasitology and Entomology, Faculty of Veterinary Medicine, Ahmadu Bello University, Zaria, Nigeria

${ }^{3}$ Department of Theriogenology and Production, Faculty of Veterinary Medicine, University of Jos, Nigeria

*Corresponding author: Paul Davou Kaze, Department of Veterinary Parasitology and Entomology, Faculty of Veterinary Medicine, University of Jos, Nigeria, E-mail: paulkaze@yahoo.com

Received date: August 05, 2017, Accepted date: August 26, 2017, Published date: August 29, 2017

Copyright: (c) 2017 Kaze PD, et al. This is an open-access article distributed under the terms of the Creative Commons Attribution License, which permits unrestricted use, distribution, and reproduction in any medium, provided the original author and source are credited.

\begin{abstract}
Eimeria tenella is the most prevalent and pathogenic Coccidia causing morbidity, mortality and resulting in serious economic losses to the poultry industry worldwide. The aim of this study was to determine the immune response of broiler chickens to Eimeria tenella developmental stages Four hundred broilers divided into six groups ( $\mathrm{n}=40$ ) were used for the study. Each group was subdivided into two $(n=20)$ as treated and non-treated and infected with different developmental stages (groups I-unsporulated oocysts, II-sporulated oocysts, III-schizonts, IV-merozoites and Vgametocytes respectively) of Eimeria tenella (local isolate), except group VI-control. The molecular identification of the local Eimeria tenella isolate identity was done through polymerase chain reaction (PCR) amplification of the genomic deoxyribonucleic acid (DNA). Clinical signs, gross caecal lesions, humoral and cellular-mediated immune response were determined in the infected broiler chickens with Eimeria tenella developmental stages. The faeces were processed using simple floatation technique and observed at 10x and 40x objectives of the Neiss microscope. Oocysts isolated from the caeca of birds naturally infected in Jos, Nigeria with the local strain were used to obtain the different developmental stages either in vitro or in vivo using bovine monocytes (schizonts), embryonated chicken eggs (gamatocytes) or two weeks old broilers (merozoites). To study the immune response elicited during the primary and secondary infection, each developmental stage was used to infect a group of two, three and half weeks old broilers, twenty of which were treated with the recommended dose of amprolium (250 mg/l (0.025\%)) for 5 days at the appearance of clinical signs. At the tertiary infection, all the experimental birds except the control group of forty birds were orally infected with 105 sporulated oocysts of known characterized virulent Eimeria tenella strain. The mean oocysts output or count was $37.07 \times 10^{6}$ in the infected birds non-treated than $25.65 \times 10^{6}$ in the treated

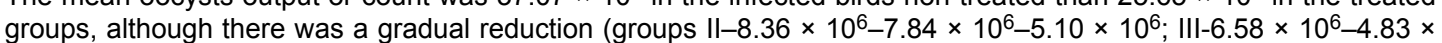

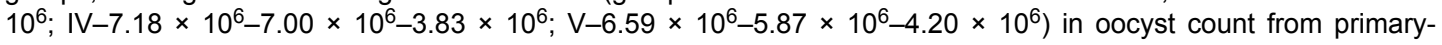
secondary-tertiary infections except group I (control). There was a significant difference in oocyst output between the groups (II and IV) $(\mathrm{p}<0.05)$.
\end{abstract}

Keywords: Eimeria tenella; Deoxyribonucleic acid; Parasite

\section{Introduction}

Eimeria tenella is an obligate intracellular protozoan parasite and is the etiologic agent of ceacal coccidiosis in domestic (free range and intensive) reared chickens and the most common and pathogenic species [1]. Avian coccidiosis is caused by intracellular protozoan's parasites belonging to seven species of Eimeria. Eimeria tenella is the most virulent causing severe heamorrhagic enteritis by infection of the epithelium and submucosa of the caeca and eventually death in infected chickens [2,3] showed that the infection can occur in both local and exotic birds with the former serving mainly as reservoir hosts. The parasite development cause diarrhea, morbidity and mortality, and has serious economic impact in the poultry industry [4]. It causes annual losses of US $\$ 2.4$ billion to the poultry industry worldwide in both the layer and broiler industries [5]. Commercial poultry production has greatly expanded in many developing countries including Nigeria due to increases in demand for animal proteins (FAO, 1998).
The aim of the study was to determine the infectivity of the different developmental stages of Eimeria tenella in broiler chickens.

\section{Materials and Methods}

\section{Study area}

The experimental settings were at the PETCA building, Anguldi, 5 kilometers from the National Veterinary Research Institute, Vom, and Jos Plateau State, Nigeria, where the laboratory work was carried out. The Jos Plateau lies on the pre-cambian from the cambian to jurasic northern Nigeria crystalline complex in central Nigeria. Its average elevation is about $1,250 \mathrm{~m}$ above mean sea level. The state is bounded on the north and west by Kaduna plains (on the average of $600 \mathrm{~m}$ above mean sea level) and on the south by Benue plains (on the average of $700 \mathrm{~m}$ above mean sea level) [6]. Geographically, the Jos Plateau is located between latitude $08^{\circ} 24^{\prime} \mathrm{N}$ and longitude $008^{\circ} 32^{\prime}$ and $010^{\circ} 38^{\prime}$ east. The land surface of Jos Plateau consists of plains, hills, depressions and todes of various forms, shapes and sizes. It is a major tourist centre in Nigeria with agriculture as the main occupation of the people. The high altitude confers on the Plateau lower temperature 
than those encountered elsewhere in Nigeria except the Obudu and Mambilla Plateau. The dry season is determined by the north easterly tropical continental air masses known as harmattan (from October April) and the wet season is the most tropical maritime air masses from May - September. The average annual rainfall is about $1,100 \mathrm{~mm}$ and is evenly distributed. Another element of climate is temperature December and January experience temperatures of below $150^{\circ} \mathrm{C}$. During February and March, the temperature rises again about $250^{\circ} \mathrm{C}$. Most of the human activities are mining and agriculture involving rearing of chickens in both the rural and urban areas for subsistency and income $[6,7]$.

\section{Experimental birds}

Four hundred (400) day-old broilers (marshal breed) were purchased from ECWA farms, Jos, brooded and used for the study. Birds were randomly distributed into six different groups of 40 each, in a clean wire cage $(n=40)$. At two weeks old, each group was again subdivided into two, treated and non-treated, of twenty broilers $(n=20)$ each. The birds were kept in a clean building, and the legs banded or labelled under strict biosecurity measures. Feed (Broiler starter, Grand cereals and oil mills, PLC, Zawan, Jos-Plateau, Nigeria) and water were provided adlibitum. The birds were vaccinated with Newcastle disease vaccine (La-Sota) at day 21 and Gomboro disease vaccines at days 14 and 28.

\section{Source and isolation of Eimeria tenella oocysts (Local isolate)}

Characterized Eimeria tenella (local isolate) sporulated oocyst isolated from naturally infected chickens in Jos, Nigeria was used for the study.

\section{In Vitro Production of Schizonts, Merozoites and Gametocytes}

\section{In vitro culture and harvesting of schizonts}

Preparation of bovine monocytes for culture of schizonts: Fifty apparently healthy 8-24 months old Hereford-Angus heifers were selected at random from the herds of the Experimental Animal Farm, College of Medical Laboratory, National Veterinary Research Institute, Vom. Blood samples were collected by jugular venipuncture using needle and tubes containing acid-citrate-dextrose (ACD) as anticoagulant. Mononuclear leucocytes were isolated by modification of the procedure of Birminghan and Jeska [8]. Briefly, the uncoagulated blood was centrifuged at $1,000 \mathrm{~g}$ for $20 \mathrm{~min}$ and the buffy coat layer collected. Contaminating red blood cells were lysed by the addition of 2 volumes of cold phosphate-buffered $(0.013 \mathrm{M})$ deionized water, and isotonicity restored with 1 volume of phosphatebuffered saline for $10 \mathrm{~min}$ after which the cells were washed 4 times with Hank's balanced salt solution (HBSS) without $\mathrm{Ca}^{2+}$ and $\mathrm{Mg}^{2+}$. The leucocytes were resuspended in Dulbecco Modified Eagle Medium (DMEM) supplemented with $50 \mu / \mathrm{ml}$ gentamycin sulphate, $15 \%$ foetal bovine serum (FBS) plus $15 \%$ horse serum (HS), the sera were previously heated in a microwave oven (DJ-M017-1, China) at $56^{\circ} \mathrm{C}$ for $30 \mathrm{~min}$. The cell cultures were incubated at $37^{\circ} \mathrm{C}$ and $5 \% \mathrm{Co}_{2}$ in an airhumidified incubator 7 days. The culture medium was changed every 2 days and on day 7 the culture medium centrifuge at $1,000 \mathrm{~g}$ for $20 \mathrm{~min}$. The harvested monocytes in the flasks were used immediately, though occasionally stored at $4^{\circ} \mathrm{C}$ until needed.

\section{Inoculation of bovine monocytes with sporulated oocysts for production and harvest of schizonts}

Each freshly prepared flask of bovine monocytes was inoculated with $10^{3}$ sporulated Eimeria tenella oocysts harvested from the infected experimental broiler chickens maintained in the Protozoology Laboratory, N.V.R.I. Vom, Nigeria. The oocyst was counted in the Mcmaster counting chamber. The cultures were then incubated for 10 days at approximately $37^{\circ} \mathrm{C}$ in a $5 \% \mathrm{CO}_{2}$, incubator with $15 \mathrm{ml}$ fresh media added every three days. Thereafter, the culture supernatant and infected cells were harvested by scraping the monolayer into the culture fluid and $1 / 20 \%$ of the culture was inoculated on the monolayer of fresh (uninfected) bovine monocytes at less than $80 \%$ confluence. The cultures were observed daily for schizonts released from the host cells and floated in the medium. The viable schizonts were collected by decanting the culture fluids followed by centrifugation at $800 \mathrm{~g}$ for $6 \mathrm{~min}$ to concentrate the schizonts. The schizonts were used immediately to orally infect the broiler chickens.

\section{Production and Harvesting of Merozoites}

The method of Stotish and Wang [9], Witlock and Danforth [10] and Xie et al. [11] were used. Briefly, Four-week-old broiler chickens were used to harvest $E$. tenella merozoites. The birds were orally infected, each with 105 sporulated $E$. tenella oocysts and sacrificed at 108,120 and $132 \mathrm{~h}$ post inoculation (p.i.). The caeca were opened and the bloody debris or caecal cores were removed by washing in Hank's Buffered Balance solution (HBSS). The mucosal surfaces were scraped with a scapel, and the tissue scraping was placed in HBSS. These materials were gently filtered through cheese cloth with HBSS [10] and merozoites in the filterate were counted in a haemocytometer.

\section{In-Vitro Production of Sporozoites by Excystation of Sporulated Oocyst}

Characterized sporulated oocysts of E. tenella (local isolates) maintained in the Protozoology Laboratory, Parasitology Division, National Veterinary Research Institute (N.V.R.I) Vom, Plateau State, Nigeria were processed for excystation to release sporozoites [12]. Briefly, purified sporulated oocysts were treated with $2.5 \%$ sodium hypochlorite for $20 \mathrm{~min}$ followed by continuous stirring in a vessel containing sterilized glass beads ( $425-600 \mu \mathrm{m}$ diameters) for $25 \mathrm{~min}$ on a magnetic stirrer. The excysted material was centrifuged at $310 \mathrm{~g}$ for $10 \mathrm{~min}$, the supernatant was discarded to remove sodium hypochlorite, and the sediment was washed three times with phosphate-buffered saline (PBS). The washed sporocysts were suspended in excystation fluid $(0.25 \mathrm{~g}$ trypsin, $4.0 \mathrm{~g}$ taurodeoxycholic acid and $0.094 \mathrm{~g}$ magnesium chloride brought to $100 \mathrm{ml}$ volume with HBSS at $\mathrm{pH}$ 7.8-8.0) followed by homogenization for 7 times (cycled on/off for 30 min on ice) at $40^{\circ} \mathrm{C}$ and $5 \% \mathrm{CO}_{2}$ ). The excysted sporozoites were obtained by centrifugation at $310 \mathrm{~g}$ for $10 \mathrm{~min}$ and stored in $\mathrm{PBS}$ at $4^{\circ} \mathrm{C}$ for further use.

\section{In Vitro Production and Harvesting of Gametocytes}

Gametocytes were generated following the protocol of Akhtar et al. [13] and Hafeez [14]. Briefly, three hundred chicken eggs (at 9 days of embryonic development; ED) were procured from a local hatchery in Jos, Plateau State kept and maintained at $39^{\circ} \mathrm{C}$ and $70 \%$ relative humidity in an incubator. Candling was performed to confirm the viability of the embryos at day $12 \mathrm{ED}$ and $0.1 \mathrm{ml}$ suspension of 
Page 3 of 7

sporozoites obtained from the the excystation of sporulated oocysts of Eimeria tenella were inoculated into chicken embryos through the chorio-allantoic membrane along with penicillin (2,000 IU) and streptomycin $(0.05 \mathrm{mg})$. The embryos were maintained at $70 \%$ humidity for 5-7 days [13]. On day $5-7$ post-inoculation, chorioallantoic fluid was collected from the dead embryos to harvest the gametocytes [14]. Gametocytes were concentrated by centrifugation at $1,500 \mathrm{~g}$ for $5 \mathrm{~min}$ and washed twice with sterile PBS and either used immediately or stored in PBS at $4^{\circ} \mathrm{C}$ until needed.

\section{Microscopy of Eimeria Tenella Developmental Stages}

Images of the Eimeria tenella developmental stages experimentally generated were taken using the Zeiss Axiorest 100 microscope connected with the cacl zeiss sony cuber shot 12.1 mega pixels monochrome CN50CC camera.

\section{Experimental Infection of Broilers with Infective Materials and Monitoring}

The experimental birds, except the control were orally given primary and secondary challenge infections with the various developmental stages of Eimeria tenella, respectively at week 2 and 3 while at week 5 of age, all birds were infected the sporulated oocyst of the parasite (Table 1). Each group was subdivided into Treated $(n=20)$ and Non- Treated $(n=20)$. In each infected group, birds in one of the subdivisions were treated with amprolium 250 WSPR Holland was administered in drinking water at a concentration of $250 \mathrm{mg} / 1$ $(0.025 \%)$ for a period of 5 days as prescribed by the Manufacturer at the appearance of visible clinical signs.

\begin{tabular}{|c|c|c|c|c|}
\hline \multirow[t]{2}{*}{ Group } & \multirow{2}{*}{$\begin{array}{l}\text { Treatment } \\
\text { and No. of } \\
\text { birds }\end{array}$} & \multicolumn{2}{|c|}{$\begin{array}{l}\text { Infection type/ Age of } \\
\text { bird }\end{array}$} & \multirow[t]{2}{*}{$\begin{array}{lr}3^{\circ} \quad \text { /wk } & 2 \\
\text { challenge } & \text { with } \\
\text { virulent } \\
\text { tenella }\end{array}$} \\
\hline & & $1^{\circ} / \mathrm{wk} 2$ & $2^{\circ} /$ wk 31/2 & \\
\hline \multirow[t]{2}{*}{ I } & $T(n=20)$ & $10^{5}$ USO & $10^{5}$ USO & $10^{5} \mathrm{so}$ \\
\hline & NT $(n=20)$ & $10^{5}$ USO & $10^{5}$ USO & $10^{5} \mathrm{so}$ \\
\hline \multirow[t]{2}{*}{ ॥ } & $T(n=20)$ & $10^{5} \mathrm{SO}$ & $10^{5} \mathrm{SO}$ & $10^{5} \mathrm{SO}$ \\
\hline & NT $(n=20)$ & $10^{5} \mathrm{SO}$ & $10^{5} \mathrm{SO}$ & $10^{5} \mathrm{SO}$ \\
\hline \multirow[t]{2}{*}{ III } & $T(n=20)$ & $10^{5} \mathrm{SCZ}$ & $10^{5} \mathrm{SCZ}$ & $10^{5} \mathrm{so}$ \\
\hline & NT $(n=20)$ & $10^{5} \mathrm{SCZ}$ & $10^{5} \mathrm{SCZ}$ & $10^{5} \mathrm{SO}$ \\
\hline \multirow[t]{2}{*}{ IV } & $T(n=20)$ & $10^{5} \mathrm{MRZ}$ & $10^{5} \mathrm{MRZ}$ & $10^{5} \mathrm{so}$ \\
\hline & NT $(n=20)$ & $10^{5} \mathrm{MRZ}$ & $10^{5} \mathrm{MRZ}$ & $10^{5} \mathrm{SO}$ \\
\hline \multirow[t]{2}{*}{ V } & $T(n=20)$ & $10^{5} \mathrm{GMT}$ & $10^{5} \mathrm{GMT}$ & $10^{5} \mathrm{SO}$ \\
\hline & NT $(n=20)$ & $10^{5} \mathrm{GMT}$ & $10^{5} \mathrm{GMT}$ & $10^{5} \mathrm{SO}$ \\
\hline VI & & 0 & 0 & 0 \\
\hline
\end{tabular}

Table 1: Experimental infection of broilers with developmental stages of Eimeria tenella. USO:Unsporulated oocyst; SO: Sporulated oocyst; SCZ: Schizoites; MRZ: Merozoites; GMT: Gametocytes; $1^{\circ}$ : primary infection; $2^{\circ}$ : Secondary infection; $3^{\circ}$ : Tertiary infection; WK: Week; T: Treated; NT: Non treated.

\section{Post-Infection Monitoring of the Birds}

Following infection, the birds were monitored daily for clinical signs, oocyst shedding and post-mortem lesions in the dead and sacrificed birds.

\section{Clinical signs}

The birds were closely observed for the appearance of visible clinical signs such as bloody faeces, ruffled feathers, huddling and mortality following infection.

\section{Oocyst shedding/counting}

The infected birds were monitored daily for oocyst shedding following primary-secondary-tertiary infections. The oocysts were quantified as follows:

Faecal samples were homogenized in a blade grinder and $2.5 \mathrm{ml}$ samples were collected from each suspension. The unsporulated oocysts were diluted in sucrose to 1: 10 to 1:10,000 and were counted microscopically in a Mcmaster chamber. Total oocyst number was calculated as oocyst count $\mathrm{x}$ dilution factor $\mathrm{x}$ (feacal sample volume/ counting chamber volume).

\section{Post-mortem examination for gross lesions}

Dead or sacrificed birds were examined for lesions of caecal coccidiosis. The broilers were sacrificed by cervical dislocation [15] at the end of each period of infection. Gross lesions were scored using the criteria set by Johnson and Reid [16] with scores ranging from 0 (no gross lesion) to 4 (extremely severe lesion) three different individuals. Score 0: no gross lesion. Score 1: A few scattered petechiae are found on the caecal wall, no thickening of the caecal walls, caecal contents present and appearing normal. Score 2: Lesions more numerous with noticable blood in the caecal contents; caecal wall somewhat thickened, but caecal contents normal. Score 3: Large amounts of blood or caecal cores present; caecal walls greatly thickened; with little if any faecal contents in the caeca. Score 4: Caecal wall greatly distended with blood or large caseous cores; faecal debris lacking or included in cores.

\section{Results}

\section{Eimeria tenella (local isolate) Developmental Stages}

The following developmental stages of Eimeria tenella were obtained in vitro:

Unsporulated oocyst: Has two layered walls, outer and inner oocyst walls and a large nucleus (Figure 1).

Sporulated oocyst: Two-layered walls, outer and inner oocyst walls and consisting of sporocyst containing sporozoites (Figure 2).

Schizonts: Ball-shape or having the shape of a bunch of oranges in bovine monocytes culture (Figure 3 ).

Merozoites: Spindle-shape with an outer pellicle (Figure 4).

Gametocytes: Spherical-shape structures (Figure 5). 
Citation: Kaze PD, Lawal I, Joseph A, Lawal S, Karaye G, et al. (2017) The Infectivity of Exo and Endogenous Stages of Eimeria tenella in Broilers. J Immuno Biol 2: 129. doi:10.4172/2476-1966.1000129

Page 4 of 7

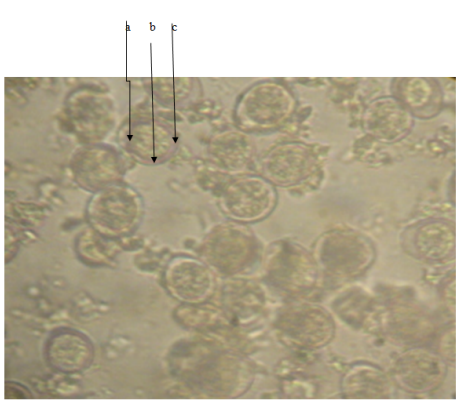

Figure 1: Unsporulated oocyst of Eimeria tenella (wet preparation $\mathrm{x} 40$ ), a: outer oocyst wall; b: inner oocyst wall; c: nuclus.

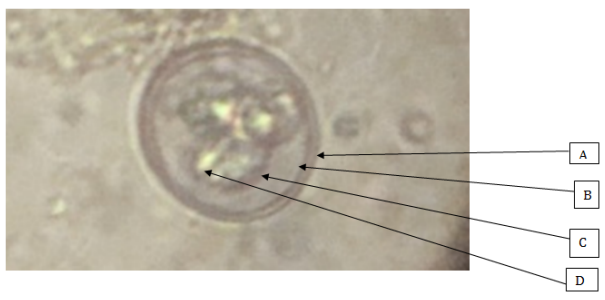

Figure 2: Sporulated oocyst of Eimeria tenella (wet preparation $\mathrm{x} 40$ ), A: Outer oocyst wall; B: Inner oocyst wall, C: Sporocyst; D: Sporozoite.

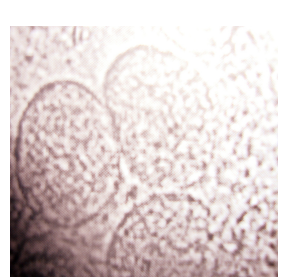

Figure 3: Schizont of Eimeria tenella (Wet preparation x40).

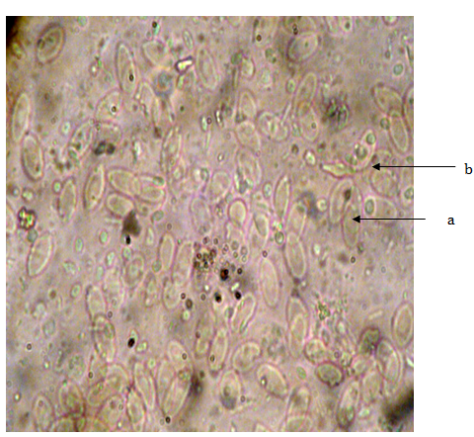

Figure 4: Merozoites of Eimeria tenella, (wet preparation x40), a: Nuclus: b: Pellicle.

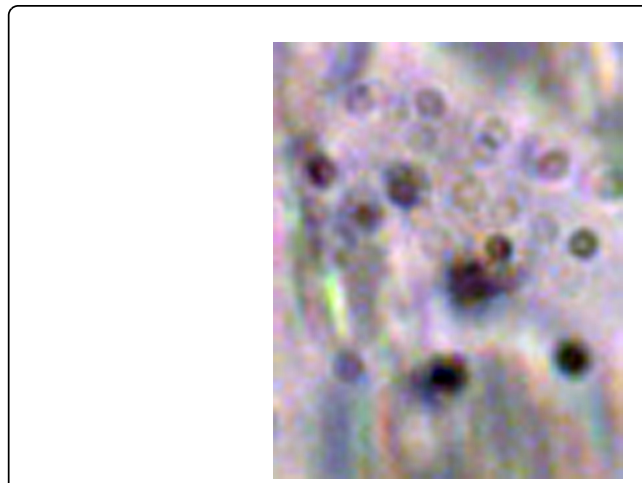

Figure 5: Gametocytes of Eimeria tenella (wet preparation x40).

\section{Clinical Signs in Broilers Experimentally Infected with Different Eimeria tenella Developmental stages}

The broilers infected with the unsporulated oocysts and schizonts showed no clinical signs or response in terms of oocyst output, bloody diarrhea or lesions, morbidity and mortality during primary infection (Tables 2.1 and 2.4). This situation was also observed at secondary infection when the birds were also infected with unsporulated oocysts. However oocyst output and reddening of serosa of the ceacum were recorded in the experimental broilers infected with schizonts at secondary infection (Table 2.1). Tertiary infection was associated with oocyst output, bloody diarrhea, ruffled feathers in the non-treated than the treated birds but no mortality was recorded in the broilers infected with the unsporulated oocyst and schizonts throughout the study period (Tables 2.1 and 2.4).

The study revealed clinical signs in the non-treated broilers infected with the sporulated oocyst and merozoites characterised by ruffled feathers, huddling, bloody diarrhoea, massive oocyst output count, severe lesions and mortality (Figure 6), (Tables 2.1 and 2.4 ) at primary and secondary infections. At tertiary infection, there was relative decrease in oocyst count (Table 2.1) and gross pathological caecal lesions (Table 2.3) but some of the infected birds recovered. The mean oocysts output or count was $37.07 \times 10^{6}$ in the infected birds nontreated than $25.65 \times 10^{6}$ in the treated groups, although there was a gradual reduction (groups II $-8.36 \times 10^{6}-7.84 \times 10^{6}-5.10 \times 10^{6}$; III $6.58 \times 10^{6}-4.83 \times 10^{6} ; \mathrm{IV}-7.18 \times 10^{6}-7.00 \times 10^{6}-3.83 \times 10^{6} ; \mathrm{V}-$ $\left.6.59 \times 10^{6}-5.87 \times 10^{6}-4.20 \times 10^{6}\right)$ in oocyst count from primarysecondary-tertiary infections except group I (control), (Table 2.1). The treated birds recovered faster from the infection than the non-treated ones. The control broilers showed neither oocyst output, caecal lesions, morbidity and mortality (Figures 7 and 8 ). There are variations in the mean prepatent period to the different stages of the parasite used for the experimental infection but the broilers infected with unsporulated oocyst showed none. The prepatent periods of 120, 264, 96 and $48 \mathrm{~h}$ were recorded when the birds were infected with sporulated oocysts, schizonts, merozoites and gametocytes respectively (Table 2.2). There was significant difference $(p<0.05)$ in oocyst output of the broilers infected by different stages of the parasite in both treated and nontreated.

Table 2.4 shows the mortality rate recorded in the infected broiler chickens with Eimeria tenella developmental stages. The non-treated birds recorded the highest mortality from primary - secondary tertiary infections $(4(3.33 \%)), 3(2.5 \%)$ and $6(5.00 \%)$ and then the 
treated birds $1(0.80 \%), 0(0.00 \%)$ and $2(1.67 \%)$ respectively. Mortality was common in broilers infected with sporulated oocysts and merozoites 1 (5.00\%), 2 (10.00\%), 0 (0.00\%). 1 (5.00\%), 1 (5.00\%), 1 $(5.00 \%)$ treated and non-treated groups indicating that these stages are virulent and initiated caecal coccidiosis in broilers. At tertiary infection mortality occurs in the entire group except control infected with a known vinular strain of Eimeria tenella sporulated oocyte.

\section{Mean gross lesions of caecal coccidiosis in broiler chickens infected with various developmental stages of Eimeria tenella}

All the categories of lesions were observed which included +4 (extremely severe lesion score),+3 (severe lesion score),+2 (moderate lesion score), +1 (mild lesion score) and 0 (no lesion scores) (Plates VI
- VIII). The +4 and +3 lesion scores were prominent in groups II and IV that were infected with sporulated oocysts and merozoites respectively at primary infection (p.i.) and the +2 and +1 scores in groups III and V at post infection. And no score in groups I at both p.i. and secondary infection (p.s.i.) respectively (Tables 2.3). At secondary infection, +3 and +2 lesion scores were observed in groups II, III, IV and $\mathrm{V}$. Tertiary infection of the broilers showed lesion scores of +2 and +1 in groups II, III, IV and V and +3 in group I. The study recorded a mean lesion score of below +3 in the experimental broilers except group II of the not treated at primary infection (Table 2.3) recorded 3.50 and the lowest mean lesion score of 1.25 in the treated groups II, IV and $\mathrm{V}$ at secondary and group IV at tertiary infections respectively (Tables 2.3). There was significant difference in the lesion scores of the study birds $(\mathrm{P}<0.05)$.

\begin{tabular}{|c|c|c|c|c|c|c|c|c|c|c|c|c|}
\hline \multirow[t]{2}{*}{ Group } & \multirow[t]{2}{*}{$\begin{array}{l}\text { Developmental } \\
\text { stage }\end{array}$} & \multicolumn{2}{|c|}{ Primary infection } & \multirow[t]{2}{*}{$P$ Value } & \multirow[t]{2}{*}{$\begin{array}{l}\text { Developmental } \\
\text { stage }\end{array}$} & \multicolumn{2}{|c|}{$\begin{array}{l}\text { Secondary } \\
\text { infection }\end{array}$} & \multirow[t]{2}{*}{$P$ Value } & \multirow[t]{2}{*}{$\begin{array}{l}\text { Developmental } \\
\text { stage }\end{array}$} & \multicolumn{2}{|c|}{ Tertiary infection } & \multirow[t]{2}{*}{$P$ Value } \\
\hline & & $T(n=20)$ & $\begin{array}{l}\mathrm{NT} \\
(\mathrm{n}=20)\end{array}$ & & & $T(n=20)$ & $\begin{array}{l}\text { NT } \\
(n=20)\end{array}$ & & & $T(n=20)$ & $\begin{array}{l}\text { NT } \\
(n=20)\end{array}$ & \\
\hline I & USO & - & - & & USO & - & - & & so & $\begin{array}{ll}2.86 & \pm \\
0.29^{d}\end{array}$ & $\begin{array}{l}2.51 \\
0.34^{\mathrm{a}}\end{array}$ & 0.001 \\
\hline II & so & $\begin{array}{ll}3.89 & \pm \\
0.43^{\mathrm{a}}\end{array}$ & $\begin{array}{ll}4.47 & \pm \\
0.76\end{array}$ & 0.947 & so & $\begin{array}{ll}3.89 & \pm \\
0.38^{\mathrm{c}}\end{array}$ & $\begin{array}{ll}3.20 & \pm \\
0.58^{\mathrm{b}} & \end{array}$ & 0.776 & so & $\begin{array}{l}2.66 \\
0.40^{c, d}\end{array}$ & $\begin{array}{ll}2.44 \\
0.34^{\mathrm{a}}\end{array}$ & 0.002 \\
\hline III & SCZ & - & - & & SCZ & $\begin{array}{ll}3.38 & \pm \\
0.32^{\mathrm{a}} & \end{array}$ & $\begin{array}{l}3.20 \\
0.58^{\mathrm{b}}\end{array}$ & 0.09 & so & $\begin{array}{l}2.79 \\
0.35^{\mathrm{c}, \mathrm{d}}\end{array} \pm$ & $\begin{array}{l}2.03 \\
0.51^{\mathrm{a}, \mathrm{b}}\end{array}$ & 0.001 \\
\hline IV & MRZ & $\begin{array}{ll}3,34 & \pm \\
0.64 & \end{array}$ & $\begin{array}{ll}3.84 & \pm \\
0.72 & \end{array}$ & 0.459 & MRZ & $\begin{array}{ll}3.54 & \pm \\
0.24^{\mathrm{b}} & \end{array}$ & $\begin{array}{l}3.46 \\
0.19^{b}\end{array}$ & 0.005 & so & $\begin{array}{l}2.20 \\
0.31^{\mathrm{a}}\end{array}$ & $\begin{array}{l}1.63 \\
0.48^{b}\end{array}$ & 0.001 \\
\hline $\mathrm{v}$ & GMT & $\begin{array}{ll}2.54 & \pm \\
0.26 & \end{array}$ & $\begin{array}{ll}3.33 & \pm \\
0.28 & \end{array}$ & 0.003 & GMT & $\begin{array}{ll}3.24 & \pm \\
0.20^{\mathrm{a}}\end{array}$ & $\begin{array}{ll}3.34 & \pm \\
0.35^{\mathrm{b}} & \end{array}$ & 0.051 & so & $\begin{array}{l}2.42 \\
0.36^{\mathrm{b}, \mathrm{c}}\end{array}$ & $\begin{array}{ll}1.78 & \pm \\
0.55^{\mathrm{b}} & \end{array}$ & 0.0003 \\
\hline
\end{tabular}

Table 2.1: Mean oocyst output (106) in the broilers infected with the different developmental stages of Eimeria tenella treated and non-treated. Groups with the same superscripts are not significantly different from each other. Groups with the different superscripts are significantly different from each other. Treated and non-treated comparison shows a significant difference in groups II and IV. USO: Unsporulated Oocyst; SO: Sporulated Oocyst; SCZ: Schizont; MRZ: Merozoites; GMT: Gametocyte; T: Treated; NT: Non Treated.

\begin{tabular}{|l|l|l|l|}
\hline Groups & $\begin{array}{l}\text { Eimeria tenella } \\
\text { developmental stages }\end{array}$ & $\begin{array}{l}\text { Dose per } \\
\text { chick }\end{array}$ & $\begin{array}{l}\text { Prepatent } \\
\text { period(hrs) }\end{array}$ \\
\hline I & Unsporulated oocyst & 105 & 0 \\
\hline II & Sporulated oocyst & 105 & 120 \\
\hline III & Schizonts & 105 & 264 \\
\hline IV & Merozoites & 105 & 96 \\
\hline V & Gametocytes & 105 & 48 \\
\hline
\end{tabular}

\begin{tabular}{|l|l|l|l|}
\hline $\mathrm{VI}$ & Control & 0 & 0
\end{tabular}

Table 2.2: Mean prepatent period of various developmental stages of Eimeria tenella in the experimental broilers. Groups with the same superscripts are not significantly different from each other. Groups with the different superscripts are significantly different from each other. Treated and non-treated comparison shows a significant difference in groups II and IV.

\begin{tabular}{|l|l|l|l|l|l|l|l|}
\hline & \multicolumn{2}{|l}{$\begin{array}{l}\text { Developmental stages used } \\
\text { for infection }\end{array}$} & \multicolumn{2}{l|}{ Secondary infection } & \multicolumn{2}{l|}{ Tertiary infection } \\
\hline & & T & NT & T & NT & T & NT \\
\hline I & Unsporulted oocyst & $0.0 \pm 0.0$ & $0.0 \pm 0.0$ & $0.0 \pm 0.0$ & $0.0 \pm 0.0$ & $2.25 \pm 1.25$ & $2.50 \pm 1.29$ \\
\hline II & Sporulated oocyst & $2.50 \pm 1.00$ & $3.50 \pm 0.58$ & $1.25 \pm 0.50$ & $2.00 \pm 0.82$ & $1.25 \pm 0.96$ & $1.50 \pm 1.29$ \\
\hline III & Schizonts & $0.0 \pm 0.0$ & $0.0 \pm 0.0$ & $0.0 \pm 0.0$ & $0.0 \pm 0.0$ & $1.75 \pm 0.96$ & $2.75 \pm 1.26$ \\
\hline IV & Merozoites & $1.75 \pm 0.50$ & $2.50 \pm 0.58$ & $1.25 \pm 0.50$ & $1.50 \pm 0.58$ & $1.50 \pm 0.50$ & $1.50 \pm 1.29$ \\
\hline
\end{tabular}


Citation: Kaze PD, Lawal I, Joseph A, Lawal S, Karaye G, et al. (2017) The Infectivity of Exo and Endogenous Stages of Eimeria tenella in Broilers. J Immuno Biol 2: 129. doi:10.4172/2476-1966.1000129

Page 6 of 7

\begin{tabular}{|l|l|l|l|l|l|l|l|}
\hline V & Gametocytes & $0.0 \pm 0.0$ & $0.0 \pm 0.0$ & $1.25 \pm 0.50$ & $1.75 \pm 0.96$ & $2.00 \pm 0.82$ & $2.25 \pm 1.71$ \\
\hline VI & 0 & 0 & 0 & 0 & 0 & 0 & 0 \\
\hline
\end{tabular}

Table 2.3: Post-Mortem mean lesion score in the experimental birds infected with Eimeria tenella developmental stages. The result showed that the mean gross lesion score was significantly higher in groups II and IV as compared to other groups $(\mathrm{p}<0.05)$ for the treated and the non-treated at primary infection. A comparison of the treated and non-treated, showed no significant difference in groups II and IV ( $p>0.05)$ respectively at secondary infection. The result showed that there was no significance in mean gross lesion score in groups II, IV and V when compared with groups I and III for both treated and non-treated $(\mathrm{p}>0.05)$. Lesion score 0 to +4 .

\begin{tabular}{|c|c|c|c|c|c|c|c|c|c|}
\hline \multirow[t]{2}{*}{ Group } & \multirow[t]{2}{*}{ Developmental stage } & \multicolumn{2}{|c|}{ Primary Infection } & \multirow[t]{2}{*}{ Developmental stage } & \multicolumn{2}{|c|}{ Secondary infection } & \multirow[t]{2}{*}{ Developmental stage } & \multicolumn{2}{|c|}{ Tertiary infection } \\
\hline & & $T(n=20)$ & NT $(n=20)$ & & $T(n=20)$ & NT $(n=20)$ & & $T(n=20)$ & NT $(n=20)$ \\
\hline 1 & USO & $0(0.00)$ & $0(0.00)$ & USO & $0(0.00)$ & $0(0.00)$ & so & $0(0.00)$ & $2(10.00)$ \\
\hline II & so & $1(5.00)$ & $2(10.00)$ & so & $0(0.00)$ & $1(5.00)$ & so & $1(5.00)$ & $1(5.00)$ \\
\hline III & SCZ & $0(0.00)$ & $0(0.00)$ & SCZ & $0(0.00)$ & $1(5.00)$ & so & $0(0.00)$ & $1(5.00)$ \\
\hline IV & MRZ & $0(0.00)$ & $1(5.00)$ & MRZ & $0(0.00)$ & $1(5.00)$ & so & $1(5.00)$ & $1(5.00)$ \\
\hline V & GMT & $0(0.00)$ & $1(5.00)$ & GMT & $0(0.00)$ & $0(0.00)$ & so & $0(0.00)$ & $1(5.00)$ \\
\hline \multirow[t]{2}{*}{$\mathrm{VI}$} & CONTROL & $0(0.00)$ & - & - & - & - & - & - & - \\
\hline & TOTAL & $1(0.80)$ & $4(3.33)$ & & $0(0.00)$ & $3(2.50)$ & & $2(1.67)$ & $6(5.00)$ \\
\hline
\end{tabular}

Table 2.4: Mortality rate (\%) recorded in the broiler chickens infected with various developmental stages of Eimeria tenella treated non-treated.

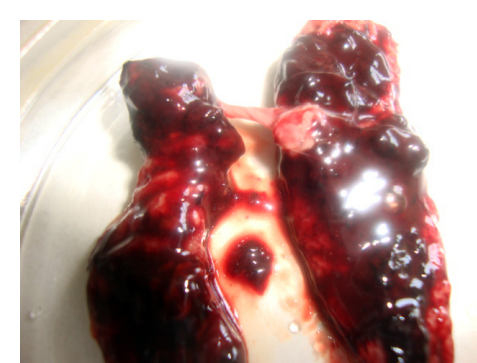

Figure 6: Ceacum of a broiler in group II infected with 105 Eimeria tenella sporulated oocyst showing ballooning and haemorrhagic ceacal plug in the lumen at slaughter after primary infection. (Lesion score +4$)$.

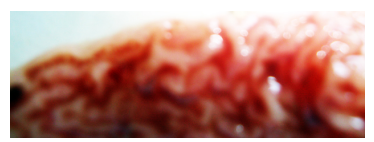

Figure 7: Thickening of the ceacum following infection of broiler with sporulated oocyst (Group II).

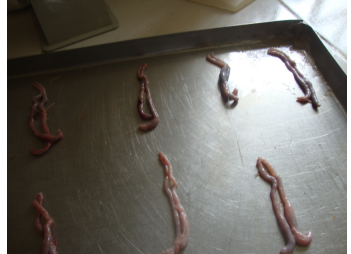

Figure 8: Ceacum of uninfected broilers (control) showing normal morphology (lesion score 0 ).

\section{Discussion}

The present study produced the various developmental stages involved in the life cycle of Eimeria tenella in the experimental birds. This is similar to the study of Randal and Woltgang et al. that also generated the different stages in the life cycle of the parasite. Clinical signs were observed in the experimental birds comprising of bloody feaces, ruffled feathers, huddling, and mortality and these clinical signs were similar to those reported by Conway and Mckenzie [17].

The varied prepatent periods associated with the infection, the unsporulated oocyst, sporulated oocyst, schizonts, merozoites and gametocytes which were $0,120,264,96$ and $48 \mathrm{~h}$ respectively are similar to the reports of Assisi et al. [18] who also recorded $120 \mathrm{~h}$ prepatent period for birds infected with sporulated oocyst of Eimeria tenella. However the prepatent periods are inconsistent with the other stages of the parasite. This may be due to differences in the potential of the parasite stages to multiply, initiate and complete cycle of development. 
There was variation in the oocyst output of the broilers infected with the various developmental stages of the parasite indicating the differences that may exist in the binding potentials of the various stages and is consistent with the reports of Talebi and Mulcahy [19] who made similar observations in Eimeria maxima infection in chickens. This variation may be due to differences in the total number of potent sporozoites released from the sporocysts, and merozoites released by the schizonts, effect of caecal content on the sporozoites and merozoites, as well as the age and genetic background of the birds [19]. This indicated that the broilers immunologically responded to the developmental stages of the parasites at different intensities or time, resulting in varied oocyst output. The observed gradual reduction in oocyst output in the treated and non-treated experimental broilers from primary- secondary - tertiary infections is similar to the report of Assisi et al. [18]. These authors reported that this may be due to the stimulation and production of immune bodies ( $\mathrm{T}$ and $\mathrm{B}$ cells) in the non-treated broilers at primary and secondary infections and action of Amprolium in the treated chickens. This is also collaborated by the findings of Chapman et al. [20].

Macroscopic lesions varied for the different periods of infection in the experimental birds. There is presently no consensus on what levels of lesions are considered clinical (requiring treatment) and subclinical [21]. However, some consider lesion higher than 1.50 per species as indicative of clinical disease, and levels below as subclinical. However, the present study recorded a mean lesion score in the experimental broilers below +3 (severe) except at primary infection were 3.50 was scored in the non-treated broilers in group II and the lowest mean lesion score of 1.25 in the treated birds in groups II, IV and V at secondary and IV at tertiary infections, respectively. This is in agreement with Kadhim [22] who recorded a mean lesion score of 3.20 for challenged broilers but inconsistent with the study of Raman [23] who observed lesion score below +2 in chickens. These variations may be due to age, genetic background of the broilers, dosage of infection, stages of the parasites administered and the environment.

\section{Conclusion}

The following can be concluded from the results obtained:

- The study successfully harvested all the Eimeria tenella developmental stages.

- The study demonstrated varying levels of oocyst outputs and gross caecal lesions in broilers infected with the different developmental stages of the parasite

- The sporozoites and merozoites showed strong infectivity and elicited stronger immune responses in infected birds, indicating that they might be potential vaccines candidates against avian caecal coccidiosis.

\section{References}

1. Gyorke A, Pop L, Cozma V (2013) Prevalence and Distribution of Eimeria species in broiler chicken farms of different capacities. Parasite 20: 50-51.
2. Mehlhorn H, Eimeria P (2005) Encyclopedia Reference of Parasitology. Biology, Structure, function. Springer, Berlin, Germany 198-199.

3. Lawal AI, Jatau ID, Musa B, Saleh U (2008) Studies on Coccidia Infection in Local Chickens (Gallus gallus domesticus) in Zaria and the Implications for the Commercial Poultry Production. J Adv Med Med Res 2: 62-65.

4. Takagi M, Kuriyagawa T, Hirose J, Ryuno T, Imura Y, et al. (2006) Anticoccidial Efficacy of Natural Herbs Extracts in calves. Adv Anim Vet Sci 5: 1096-1100.

5. Chandrakesan P, Muralidaran K, Kumar VD, Ponnudarai G, Harikrishnan TJ, et al. (2009) Efficacy of Herbal Complex against Caecal coccidiosis in Broiler Chickens. Veterinarski Arhiv 79: 123-199.

6. PADP (2002) Plateau Agricultural Development Programme. Annual Report 2002.

7. Food and Agricultural Organisation (2006) Diseases of Agricultural Farm Animals. Querterly Bulletin of Statistics 1: 33-37.

8. Birminghan JR, Jeska EL (1980) The isolation, long-term cultivation and characterization of peripheral blood monocytes. Immunology 41 : 807-814.

9. Stotish RL, Wang CC (1975) Preparation and purification of merozoites of E. tenella. J Parasitol 10: 327-330.

10. Witlock D, Lushbaugh W, Danforth H, Ruff M (1975) Scanning electron microscopy of the cecal mucosa in Eimeria-tenella-infected and uninfected chickens. Avian Dis 19: 293-304.

11. Xie MQ, Gilbert JM, Fuller AL, McDongald LR (1990) A new method for purification of Eimeria tenella Merozoites. Parasitol Res 76: 566-569.

12. Speer CA, Hammond DM, Mahrt JL, Roberts WL (1973) Structure of the oocysts and sporocysts walls and excystation of sporocysts walls and excystation of sporozoites of Isospora canis. J Parasito 59: 35-40.

13. Akhatar M, Ayaz MM, Hayat CS, Ashfaque M, Hussani I (2002) Adaptation of Eimeria tenella sporozoites (local isolates) in embryonated hen's eggs. J Vet Sci 22: 40-41.

14. Hafeez MA (2005) Immunogenic characterization of Eimeria tenella gametocytes antigen as vaccine against cocidioses in poultry.

15. CFMV (2002) Conselloo Federal de Medicina Veternaria (CFMV).

16. Johnson J, Reid WM (1970) Anticoccidial drugs : Lesion scoring techniques in battery and floor pen experiment with chickens. Exp Parasitol 28: 30-36.

17. Conway DP, Mckenzie ME (2007) Poultry Coccidiosis Dignostic and Testing Procedures, Third Edition.

18. Assisi RCL, Curry MC, Luns FD, Assis RL (2012) Anticoccidial efficacy of drinking water soluble diclazuril experimentally infected broiler chicken. Arq Bras Med Vet Zootec 64: 6-8.

19. Talebi A, Mulcahy J (1995) Correlation between immune responses and oocyst production in chickens monospecifically infected with Eimeria maxima. Avian Pathol 24: 485-495.

20. Chapman H (2008) Evaluation of the efficacy of anticoccidial drugs against Eimeria species in the fowl. Int J Parasitol 28: 1141-1144.

21. Maartan DG (2013) Coccidiosis in poultry: Review on diagnosis, control, prevention and interaction with overall gut health: In proceedings European Symposium of Poultry Nutrition.

22. Kadhim LI (2014) Histopathological changes of broilers immunized with sonicated oocysts against Eimeria tenella. International Journal of Advanced Biological Research 4: 31-35.

23. Raman (2011) Lesion scoring techniques for assessing the virulence and pathogenecity of Eimeria species. Veterinary arhive 81: 259-271. 